\title{
Factors Affecting College Students' Effectiveness for Cooperative Learning through Structural Equation Modelling
}

\author{
Sangeeta Sharma ${ }^{1, *}$, Arpan Bumb ${ }^{2}$ \\ ${ }^{1}$ Department of Humanities and Social Sciences, Birla Institute of Technology and Science, India, ORCID ID: 0000-0002-2179-8264 \\ ${ }^{2}$ Birla Institute of Technology and Science, India, ORCID ID: 0000-0001-5952-7307
}

Received May 28, 2020; Revised July 2, 2020; Accepted July 29, 2020

\section{Cite This Paper in the following Citation Styles}

(a): [1] Sangeeta Sharma, Arpan Bumb, "Factors Affecting College Students' Effectiveness for Cooperative Learning through Structural Equation Modelling," Universal Journal of Educational Research, Vol. 8, No. 9, pp. 4080-4088, 2020. DOI: 10.13189/ujer.2020.080933.

(b): Sangeeta Sharma, Arpan Bumb (2020). Factors Affecting College Students' Effectiveness for Cooperative Learning through Structural Equation Modelling. Universal Journal of Educational Research, 8(9), 4080-4088. DOI: 10.13189/ujer.2020.080933.

Copyright $\odot 2020$ by authors, all rights reserved. Authors agree that this article remains permanently open access under the terms of the Creative Commons Attribution License 4.0 International License

\begin{abstract}
The substantial changes in the education system have pushed the teachers to go back to the earlier practice of cooperative learning so as to enable students to realize their achievement through group activities. Cooperative learning is a multi-layered activity as it involves various factors such as proper instructions, feedback, team structure, leadership, etc. The study aims to provide a model of various factors that affect the different outcomes of cooperative learning using structural equational modelling (SEM). The exploratory factor analysis is utilized to develop the model by grouping the factors under two latent variables. The latent variables observed are factors related to individual or intrinsic factors and factors related to external environment or extrinsic factors. The outcomes of the effectiveness of cooperative learning are linked with these two factors. The results indicate that individual factors have an indirect effect and external factors have a direct effect on the outcomes of cooperative learning. This study provides an overall idea about how the various factors influence the outcomes of cooperative learning by using a multivariate approach and allows perceiving the impact of factors simultaneously. Further, some recommendations are also made on how to improve the outcomes and effectiveness of the cooperative learning method. This study will help the teachers, academicians, and administrators to develop strategies according to the model prescribed by this study to maximize the outcomes of cooperative learning.
\end{abstract}

Keywords Cooperative Learning, Instructions, Exploratory Factor Analysis, Structural Equational Modeling

\section{Introduction}

Cooperative learning enables the students to shed their inhibitions and learn better with the support of their peers. The shared goals, tasks, learning outcomes, efforts make cooperative learning a group activity. In order to achieve a desired outcome in terms of results, a group involvement is necessary.

The learning becomes a faster and enjoyable experience if the instructions are imparted with clarity. The role of the teacher is in fact more in cooperative learning because the steps in execution for lectures increase. Ideally, if the efforts are made meticulously to make balanced teams in terms of the intelligence and reception level, the efficiency of the cooperative learning is better. In today's time, a number of techniques is implemented to improve the learning, cooperative method is one of the popular ways as it is less intrusive.

\subsection{Background for the Study}

Cooperative learning is one of the most widely 
researched topics in education and involves the active engagement of students and instructor alike. Ever since its genesis in the 1970s, cooperative learning is being visualized as an effective tool for classrooms [1-3]. Cooperative learning style has been used in a variety of learning institutions ranging from pre-school to graduate school levels [4]. Cooperative learning is a learning activity in which students having different backgrounds, work together for a common project or task, in which they are accountable for working individually and group as a whole [5]. Each of the learning goals can be accomplished by students if members of the team are able to complete the given tasks [6]. Cooperative learning can enhance the level of interaction in the class and allows a greater grasping and retention of the concepts taught in the classroom [49]. The past researches by [7-13] have shown that cooperative learning improves the academic achievement as well as the social skill development of the students. There has been an increase in using cooperative learning practices in a range of domains. The impact of cooperative learning has been recognized in under-graduate level courses such as Engineering involving statistics [14], mechanics [51], mathematics [52], chemistry [15,17] etc. Cooperative learning has been used in Nursing [16] with courses including maternal and newborn health [53], communication [54] etc. Further, the impact of cooperative learning in high school subjects like Mathematics [18], English language [19], Geography [55] etc. has been explored thoroughly. These studies were conducted in different countries such as Australia, Ethiopia, Indonesia, India, the United States of America and the United Kingdom from the year 2007 to 2020.

A majority of past studies have concluded a significant increase in learning and interaction by using cooperative learning as compared to individualistic learning. Cooperative learning is also related to prevent and treat a variety of social problems such as low self-esteem, violence, bullying, alienation, psychological pathology, egocentrism [40-43]. However, there are some reservations regarding the utilization of cooperative learning, as many of the teachers are not well-trained for executing instructions and are happy with the traditional classroom as it is a shortcut method of learning [37].

Cooperative learning is perceived as a tool to prepare students to work in a team environment, which is utilized in many of the employment settings [21]. These situations enable students to learn from each other. The shared goal allows the whole group to channelize an individual member's strengths. Cooperative learning has also been identified to improve many of the important attributes for predicting success at work such as emotional intelligence [44]. Slavin [28] has described three elements for classroom instructional technology- task structure (activities in school such as lecture, class discussion etc.), reward structure (rewards for a particular behavior; including grades, teacher's approval and tangible rewards) and authority structure (control over activities of students). Cooperative learning changes these three elements especially in the task structure as interpersonal reward changes to group reward. The rewards are based on performance and cohesiveness. The model given by $[33,34,7,8]$ is widely used in education because of its simplicity. It has presented five advantages of cooperative learning- reflection and planning; interpersonal learning skills; responsibility development; capability to interact simultaneously and inculcate positive interdependence.

The studies on techniques for cooperative learning are based on four major models - Teams-Games-Tournament [29] which involves assigning students to different teams while maintaining heterogeneity and then prepare the members for a tournament; members study together to ensure the preparedness of everyone. During the tournament, the competition is made fair by seeding the best and worst performers together. Student Teams-Achievement Division [30] uses the same format in [29] to generate teams and students are asked to answer a quiz after studying with their teams for 15 minutes. In the Jigsaw technique [31], students are dependent on each other for success as in this, assignments are divided into small parts that are completed by groups. Each of the groups must assemble the pieces to complete the assignment or Jigsaw. In Small group teaching [32] students divide themselves into groups and choose a particular subtopic under a general theme prescribed by the teacher and give a presentation on it. This is evaluated by the teacher and other students. In some of the other studies, students are involved in a simple cooperative technique $[33,34]$ in which students are assigned into groups and asked to work as a team.

Factors that affect the outcome of cooperative learning by student's perspective are lack of motivation, awareness, past academic performance and GPA. In the study by [36], it is concluded that in order to make cooperative learning effective instructors should make paired assignments keeping in mind the past performance of the students, that is, creating pairs by including students having low, medium and high academic performances. It also concluded that student characteristics have an indirect effect on student's learning efficiency through cooperative learning. Other factors identified are a shortage of resource materials, bottlenecks in the team, dependence on high performing members, lack of instructions, lack of training and feedback $[23,38,39]$.

\subsection{Research Gap}

There is a number of studies which are devoted to understanding the benefits of cooperative learning $[22,23]$ and to identify best practices to execute the cooperative learning [28-34]. The other studies have also elaborately dealt with attitudes towards the technique [24-26] and the role of teacher in cooperative learning [35]. However, 
factors that influence the effectiveness of the cooperative learning have not been studied in detail and depth. Some of the studies have presented empirical evidences while considering only one factor for determining the effectiveness of cooperative learning. There are only a few studies in which multiple factors related to individual, environment and group are considered. In some studies, when multiple factors utilized the method to analyze the response is ANOVA [20] which does not present a complete picture as the impact of only one factor can be seen at a time while using this statistical tool.

Hence, there is a need to develop an effective method that can project the impact of multiple factors at the same time. This paper aims to provide a model considering the multivariate nature of the factors. Structural Equational Modelling (SEM) [27] is a technique that can use multivariate analysis and therefore is applied in this paper. SEM is more confirmatory and identifies the relationship between latent and observed variables. This statistical tool is used to validate the hypotheses presented in the next section.

\subsection{Problem Statement and Hypotheses}

This paper aims to provide a concrete estimate about the factors affecting the outcomes of the cooperative learning from the perspective of students. From the past studies, the variables are either related to individual or intrinsic factors and external environment or extrinsic factors. Hence, these two were chosen as latent variables. The factors are identified through past studies and they are categorized under these latent variables. The hypotheses for the study are-

H1: Intrinsic factors will have a positive and significant effect on extrinsic factors.

H2: Intrinsic factors will have a positive and significant effect on outcomes of learning through cooperative learning.

H3: Extrinsic factors will have a positive and significant effect on outcomes of learning through cooperative learning.

\subsection{Objectives of the Study}

- To find out the outcomes of cooperative learning.

- To identify the factors which increase the effectiveness of cooperative learning and develop Structural Equation Model for the same.

- To recommend the necessary course of action for improving the effectiveness of the cooperative learning

\subsection{Significance of the study}

This study would allow teachers, academicians and administration to focus on certain factors and improve the effectiveness of cooperative learning. It would also make students, teachers and administrative authorities aware of the benefits of using cooperative learning in the classroom and ensure that students and teachers understand the importance of their role in order to make this technique effective. It will also enable teachers to identify what are the expectations of students so that they can align the lecture according to the expectations. This study will facilitate the practitioners to identify the area of improvement by comparing the results to the model and make strategies accordingly.

\subsection{Limitations of the Study}

One of the limitations is the error term associated with each of the latent variables measured. Although fit indices report a good fit, there are minor errors associated with the model. Some of the errors associated might be due to the measures from questionnaire elements. Other limitation is the nature of respondents as many of them have not experienced all forms of cooperative learning, therefore some of the effects of cooperative learning are not perceived. Further, a greater number of factors and measures for effectiveness can be included. As students were not in the intervention for a long period, bias towards cooperative learning can be formed.

\section{Materials and Methods}

\subsection{Design and Method}

The following factors are identified through the past researches discussed in section 1.1 that have an effect on outcomes of learning through cooperative learning.

Table 1. Factors affecting cooperative learning

\begin{tabular}{|c|c|c|}
\hline S.no & Factor & Identifier \\
\hline 1. & Motivation & M \\
\hline 2. & Interaction & IT \\
\hline 3. & Competition & $\mathrm{CO}$ \\
\hline 4. & Skills & SK \\
\hline 5. & Leadership & $\mathrm{L}$ \\
\hline 6. & Instruction & IS \\
\hline 7. & Feedback & $\mathrm{F}$ \\
\hline 8. & Duration & $\mathrm{D}$ \\
\hline 9. & Assignment Credits & $\mathrm{AC}$ \\
\hline 10. & Resource Material & $\mathrm{RM}$ \\
\hline 11. & Team Size & $\mathrm{TS}$ \\
\hline 12. & Team Composition & $\mathrm{TC}$ \\
\hline 13. & Cooperation in Teams & CT \\
\hline 14. & Communication & $\mathrm{CM}$ \\
\hline
\end{tabular}

The outcomes for cooperative learning are identified 
through the following parameters that have been identified by the past studies discussed in section 1.1.

Table 2. Outcomes of cooperative learning

\begin{tabular}{|c|c|c|}
\hline S.no & Factor & Identifier \\
\hline 1. & Retention & R \\
\hline 2. & Fast Learning & FL \\
\hline 3. & Openness to different Ideas & OT \\
\hline 4. & Planning and Organization & PO \\
\hline 5. & Interactive Abilities & IA \\
\hline 6. & Reducing Inhibition & RI \\
\hline
\end{tabular}

\subsection{Participants}

The total number of participants for the study was 212 . The demographic details of the sample studied were noted in the age group of 17-34 years and comprised of $29.24 \%$ (62) females and $70.7 \%$ (150) males. The participants were chosen through a random sampling method from three different institutions. The sample comprised of students pursuing various degree programs in pure sciences, engineering and pharmacy. Each of the respondents had participated in some form of cooperative learning activity in their courses either as a learning activity or a graded project. The pairing for the majority of students was done through the Jigsaw method [31], in which the students were asked to discuss their views on a specific topic and then share it with the rest of the class.

\subsection{Instruments}

A questionnaire was developed in order to identify the impact of factors on the effectiveness of cooperative learning. The questionnaire consisted of the following sections-

\section{- Comparison of learning from cooperative learning}

In this section, participants were asked whether the learning from the cooperative method was as effective as compared to traditional classroom-based models with no interaction. This question captured dichotomous responses in either Yes or No.

- Factors affecting the effectiveness of cooperative learning
This section involved participants to rate the effect of factors identified in Table 1 on the effectiveness of cooperative learning, on the scale of 1-5 where the following ratings were mentioned: 1-least influence, 2-little influence, 3-moderate influence, 4-significant influence, 5-most influence.

- Measures for outcomes of the effectiveness of cooperative learning

In this section, participants were asked to rate the overall effectiveness parameters through cooperative learning as identified in Table 2. The rating was mentioned as a learning outcome from cooperative learning on a scale of 1-5 where 1-least, 2-little, 3-moderate, 4-significant, 5 -most.

Apart from these, general demographic data such as age, gender, institute etc. was collected to gauge the nature of the respondents.

\subsection{Analysis of the Responses}

The responses were analyzed using IBM SPSS, AMOS 26.0 and $\mathrm{R}$. The procedure after collecting the response was explained further. First, the reliability test was done in order to ensure the internal dataset reliability of the questionnaire developed by computing the Cronbach alpha for each of the scale items mentioned in the instruments section. In order to identify whether the sample collected was adequate or not, KMO test was performed. After obtaining adequate values, a number of factors were determined by using eigenvalue criteria viz. the factors having eigenvalue greater than 1 . By substituting the number of factors and rotation type to varimax, a model was obtained and further hypothesis was validated.

\section{Results}

Cronbach alpha value for the overall questionnaire was 0.878 . The value for the intrinsic group is 0.891 , the extrinsic group is 0.813 and the outcomes/results group is 0.866 . The high value of Cronbach alpha indicates that the factors in their respective groups are closely related and the data is consistent.

The KMO index for each of the items was computed and is presented in the following table 3 . 
Table 3. KMO values for questionnaire items

\begin{tabular}{|c|c|c|c|}
\hline S.no & Factor & Identifier & KMO \\
\hline 1. & Motivation & $M$ & 0.79 \\
\hline 2. & Interaction & IT & 0.92 \\
\hline 3. & Competition & $\mathrm{CO}$ & 0.85 \\
\hline 4. & Skills & SK & 0.91 \\
\hline 5. & Leadership & $\mathrm{L}$ & 0.90 \\
\hline 6. & Instruction & IS & 0.85 \\
\hline 7. & Feedback & $\mathrm{F}$ & 0.90 \\
\hline 8. & Duration & $\mathrm{D}$ & 0.75 \\
\hline 9. & Assignment Credits & $\mathrm{AC}$ & 0.83 \\
\hline 10. & Resource Material & RM & 0.86 \\
\hline 11. & Team Size & $\mathrm{TS}$ & 0.92 \\
\hline 12. & Team Composition & $\mathrm{TC}$ & 0.90 \\
\hline 13. & Cooperation in Teams & $\mathrm{CT}$ & 0.84 \\
\hline 14. & Communication & $\mathrm{CM}$ & 0.90 \\
\hline 15. & Retention & $\mathrm{R}$ & 0.90 \\
\hline 16. & Fast Learning & FL & 0.88 \\
\hline 17. & $\begin{array}{l}\text { Openness to different } \\
\text { Ideas }\end{array}$ & OT & 0.82 \\
\hline 18. & $\begin{array}{l}\text { Planning and } \\
\text { Organization } \\
\end{array}$ & $\mathrm{PO}$ & 0.82 \\
\hline 19. & Interactive Abilities & IA & 0.90 \\
\hline 20. & Reducing Inhibition & RI & 0.87 \\
\hline
\end{tabular}

The overall KMO index was 0.88 which is more than the recommended value of 0.5 which indicates that the collected sample is adequate in terms of construct validity and the number of observations is adequate for applying factor analysis. To calculate the number of factors, the components having eigenvalues greater than 1 were selected from Table 4, which is formed by using principal component analysis. Hence, a total of three components or latent variables were identified which explained $68.81 \%$ of the variance. The first component deals with the extrinsic factors and explains $51.52 \%$ of the variance and the second component deals with intrinsic factors and explains $10.34 \%$ of the variance. The third component deals with the effectiveness parameters. The results are shown in Table 4.

In order to identify which of the factors are part of intrinsic and extrinsic latent variables exploratory factor analysis is used with principal component analysis and varimax rotation. The following table shows the results. The factors having a value of greater than 0.45 are included in the particular latent variable which is shown in the boldface in Table 5 .

From Table 5, it is clear that intrinsic factors comprised of Motivation, Interaction, Competition, Skills and Duration. Extrinsic factors comprise of Instructions, Feedback, Assignment credits, Resource materials, Team size, Team composition, Leadership, Cooperation in team and Communication. The effectiveness parameters were Fast learning, Retention, Openness to different ideas, Planning and organization, Interactive abilities and Reducing inhibitions.

The exploratory factor analysis is valid as the RMSEA value is 0.071 and is sufficient, TLI is 0.91 which is more than an ideal value of 0.9 , RMSR is 0.04 . After obtaining the path diagram from the exploratory factor analysis, Structural Equation Modelling is used to test the hypotheses. The following Figure 1 depicts the path diagram used.

Table 4. Eigenvalues and number of factors

\begin{tabular}{|c|c|c|c|c|c|c|}
\hline \multirow{2}{*}{ Component } & \multicolumn{3}{|c|}{ Initial Eigenvalues } & \multicolumn{3}{|c|}{ Extraction Sums of Squared Loadings } \\
\hline & Total & $\%$ of Variance & Cumulative $\%$ & Total & $\%$ of Variance & Cumulative $\%$ \\
\hline 1 & 7.213 & 51.518 & 51.518 & 7.213 & 51.518 & 51.518 \\
\hline 2 & 1.448 & 10.341 & 61.859 & 1.448 & 10.341 & 61.859 \\
\hline 3 & 1.374 & 6.958 & 68.817 & 1.374 & 6.958 & 68.817 \\
\hline 4 & .942 & 6.083 & 74.899 & & & \\
\hline 5 & .812 & 5.372 & 80.272 & & & \\
\hline 6 & .631 & 3.790 & 84.062 & & & \\
\hline 7 & .444 & 3.168 & 87.230 & & & \\
\hline 8 & .408 & 2.916 & 90.146 & & & \\
\hline 9 & .327 & 2.339 & 92.485 & & & \\
\hline 10 & .300 & 2.143 & 94.628 & & & \\
\hline 11 & .275 & 1.966 & 96.594 & & & \\
\hline 12 & .201 & 1.436 & 98.030 & & & \\
\hline 13 & .140 & 1.000 & 99.030 & & & \\
\hline 14 & .136 & .970 & 100.000 & & & \\
\hline
\end{tabular}


Table 5. Factor loadings and values

\begin{tabular}{|c|c|c|c|}
\hline \multirow{2}{*}{ Factor } & \multicolumn{3}{|c|}{ Component } \\
\hline & 1 & 2 & 3 \\
\hline Motivation & .206 & .800 & .310 \\
\hline Interaction & .382 & .681 & .219 \\
\hline Competition & .286 & .649 & .210 \\
\hline Skills & .446 & .626 & -.011 \\
\hline Leadership & .538 & .410 & .165 \\
\hline Instruction & .473 & .524 & .355 \\
\hline Feedback & .544 & .383 & .289 \\
\hline Duration & -.043 & .800 & .111 \\
\hline Assignment Credits & .784 & -.040 & .134 \\
\hline Resource Material & .778 & .273 & .219 \\
\hline Team Size & .754 & .154 & .364 \\
\hline Team Composition & .782 & .404 & .112 \\
\hline Cooperation in Teams & .709 & .465 & .471 \\
\hline Communication & .763 & .419 & .133 \\
\hline Retention & .212 & .401 & .614 \\
\hline Fast Learning & .301 & .061 & .801 \\
\hline Openness to different Ideas & .112 & .147 & .714 \\
\hline Planning and Organization & -.041 & .127 & .514 \\
\hline Interactive Abilities & .311 & -.051 & .666 \\
\hline Reducing Inhibition & .143 & .311 & .687 \\
\hline
\end{tabular}

Extraction Method: Principal Component Analysis.

Rotation Method: Varimax with Kaiser Normalization.

\section{a. Rotation converged in 3 iterations.}

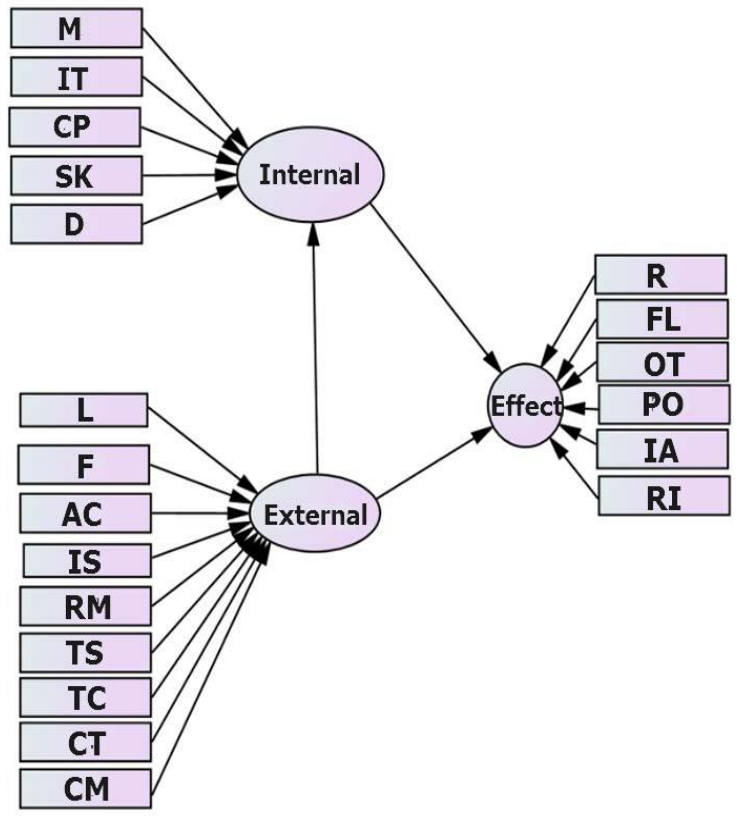

Figure 1. Path diagram

The results of SEM are summarized in the following figure.

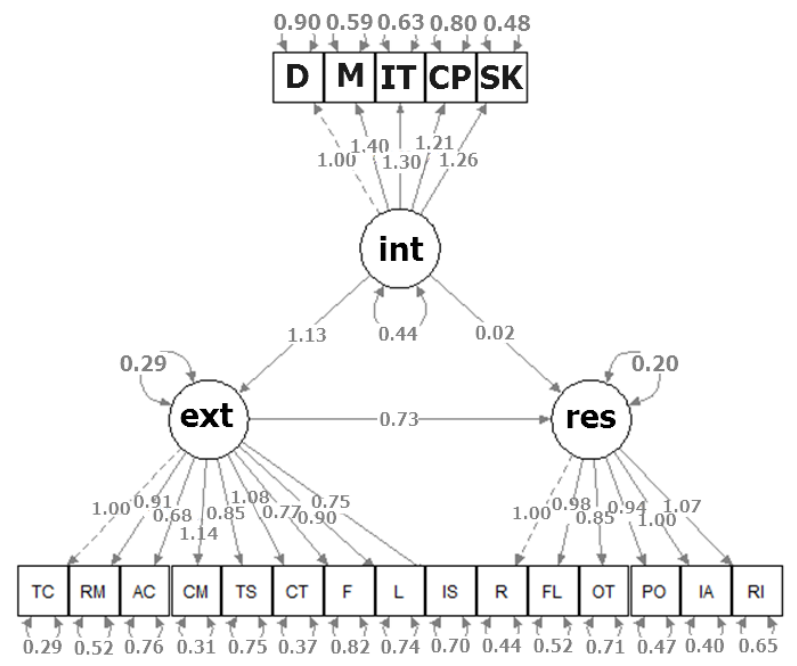

Figure 2. SEM Results

As observed from Figure 2, the path estimates amongst the observed factors in latent variables i.e. internal, external and result, are significant as the value for each of the paths is greater than 0.5. The following fit indices are also obtained for this model: RMSEA-0.072, GFI-0.92, TLI-0.90, AGFI-0.91. These measures indicate that the model is having a good fit on the variables measured.

The hypotheses were tested on two criteria- critical ratio should be greater than 2.5 and p-value should be less than 0.05 . The following table shows the results for acceptance or rejection of the hypotheses proposed. 
Table 6. Hypotheses test results

\begin{tabular}{|c|c|c|c|c|}
\hline S. No. & Hypothesis & Critical Ratio & p-value & Result \\
\hline H1 & $\begin{array}{c}\text { Intrinsic factors will have a positive and } \\
\text { significant effect on extrinsic factors }\end{array}$ & 4.24 & 0.000 & Accepted \\
\hline H2 & $\begin{array}{c}\text { Intrinsic factors will have a positive and } \\
\text { significant effect on the effectiveness of } \\
\text { learning through cooperative learning. }\end{array}$ & 0.079 & 0.937 & Rejected \\
\hline H3 & $\begin{array}{c}\text { Extrinsic factors will have a positive and } \\
\text { significant effect on the effectiveness of } \\
\text { learning through cooperative learning. }\end{array}$ & 4.018 & 0.000 & Accepted \\
\hline
\end{tabular}

\section{Discussion}

191 of the participants $(90.09 \%)$ opinionated that learning from the cooperative method is more effective than the traditional method of learning. The cooperative method involves free participation in class activities, discussion, critical reasoning and strategic learning and students tend to be more active as compared to traditional classroom methods. Hence, cooperative learning is an effective tool and leads to increased interest in learning, overall student satisfaction and engagement. This particular result is in lieu with almost all the past studies in the topic such as [7-13,45]. Cooperative learning shifts the realm of discussions from teacher centric to student centric and therefore increases the level of involvement of students and presents an opportunity for the students to interact amongst themselves and learn the concepts together. Cooperative learning also encourages the students to focus on helping each other understand the concepts of a topic, due to which increase in learning is observed.

The intrinsic factors including Motivation, Interaction, Competition, Skills and Duration are individualistic. Any factor in this is related to individual's behavior, integrity and thinking.

An individual has control over intrinsic factors and they play a central role in participation in the team. These factors impact the extrinsic factors as intrinsic factors such as motivation, interaction, skills etc. shape the outcome of extrinsic factors, i.e. without intrinsic factors extrinsic variables such as team cooperation, communication etc. won't be able to help much in the effectiveness of the cooperative learning.

Extrinsic factors have a positive and significant impact on the measures of the outcome of cooperative learning as hypothesis 3 is accepted. This result is in accordance with the past studies, which concluded that factors such as team cooperation, size and communication [40,42,48], leadership [25,26], instructions [50,40] are essential for the effectiveness and outcomes of cooperative learning.

The study concluded that intrinsic or individualistic factors do not directly affect outcomes of cooperative learning, this may be due to the group environment necessary for cooperative learning. In cooperative learning, the impact of external, group and team factors are more relevant as they create greater impact than individuals. However, as intrinsic factors drive the extrinsic factors which in turn drive the outcomes of cooperative learning; intrinsic factors indirectly affect the outcomes of cooperative learning. There have been a few studies [46] in which there are concerns about the individual factors over the outcomes of cooperative learning and individual factors affecting cooperative learning are not supported by the hypotheses. Moreover, the previous studies by [47] have shown a greater role of team learning and instructor in positive outcomes of cooperative learning.

Therefore, to improve the outcomes of cooperative learning effort must be made to improve the external factors as they directly influence the outcomes and are easy to alter. For example, factors such as leadership, team composition, team size, communication, assignment credits etc. can be changed easily and impact the outcome significantly. Since intrinsic factors have an indirect effect on cooperative learning, a conscious effort should be made to improve the individual or intrinsic factors to maximize the outcome of cooperative learning.

\section{Conclusions}

The study concluded that the effectiveness of cooperative learning is more as it led to higher retention, openness to different ideas, fast learning, and interactive abilities. The researchers had developed a model using exploratory factor analysis and structural equational modelling for explaining the outcomes of cooperative learning by forming paths in the model. The latent variables were identified by using exploratory factor analysis. The learning is more from the cooperative method as compared to the traditional form as more than $90 \%$ of the participants rated that they believe cooperative learning is more effective than the traditional counterpart. This is mainly due to the higher interest and interaction between the students about the concepts taught in the class. By the results, it is concluded that intrinsic or individual factors do not have a direct impact on the outcomes and perceived benefits of the cooperative learning, while external or extrinsic factors have a direct role to play. However, intrinsic factors do have an indirect impact as they significantly influence the extrinsic factors. Therefore, practitioners should focus on developing strategies that influence the positive external environment necessary for cooperative learning. By using the 
cooperative learning methods students are likely to improve their academic performance.

\section{Acknowledgments}

We are very grateful to participants for filling out the questionnaire.

\section{REFERENCES}

[1] Artzt, A. \& Newman, C., How to use cooperative learning in the mathematics classroom. (2nd ed.), The National Council of Teachers of Mathematics, Inc: USA.R. F. Voss, J. Clarke. Algorithmic Musical Composition, Silver Burdett Press, Londyn, 1997.

[2] Gillies, R. M., Structuring cooperative group work in classrooms, International Journal of Educational Research, Vol.39, No.1-2, 35-49, 2003. http://dx.doi.org/10.1016/S08 830355(03)00072-7.

[3] Sutton, G., Cooperative learning works in mathematics, Mathematics Teacher, Vol. 85 No.1, 63-66, 1992.

[4] Johnson, D. W., Johnson, R. T., \& Stanne, M. B., Cooperative learning methods: A meta-analysis, 2000.

[5] Siegel, C., Implementing a research-based model of cooperative learning, The journal of educational research, Vol. 98 No.6, 339-349, 2005.

[6] Deutsch, M., Cooperation and trust: Some theoretical notes. In M. R. Jones (Ed.), Nebraska symposium on motivation, 275-319, Lincoln, NE: University of Nebraska Press, 1962.

[7] Johnson, D. W, \& Johnson, R. T., Effects of cooperative and individualistic instruction on handicapped and non-handicapped students, The Journal of Social Psychology, Vol. 118, 257-268, 1982.

[8] Johnson, D. W, \& Johnson, R. T., The socialization and achievement crisis: Are cooperative learning experiences the answer? Applied Social Psychology, Vol. 4, 199-224, 1983.

[9] O'Melia, M. C, \& Rosenburg, M. S., Effects of cooperative home work teams on the acquisition of mathematics skills by secondary students with mild disabilities, Exceptional Children, Vol. 60, 538-548, 1994.

[10] Qin, Z., A meta-analysis of the effectiveness of achieving higher order learning tasks in cooperative learning vs. competitive learning, Unpublished doctoral dissertation, University of Minnesota, 1992.

[11] Qin, Z., Johnson, D. W., \& Johnson, R. T., Cooperative vs. competitive efforts and problem solving, Review of Educational Research, Vol. 65, 129-143, 1995.

[12] Mabrouk, P. A., Active Learning: Models from the Analytical Sciences, Washington, DC: American Chemical Society, 2007.

[13] Aragaw D., The Effect of Cooperative Learning On Students Efl Reading Comprehension: Meshentie Grade 9 High
School Students, Educational Journal, Vol. 4, No.5, 222-231, 2015, doi-10.11648/j.edu.20150405.16

[14] Donohue, S. K., \& Richards, L. G. (2009, October). Factors affecting student attitudes toward active learning activities in a graduate engineering statistics course, In 2009 39th IEEE Frontiers in Education Conference, 1-6. IEEE, 2009.

[15] Tarhan, L., \& Acar, B., Problem - based learning in an eleventh grade chemistry class:'factors affecting cell potential', Research in Science \& Technological Education, 25(3), 351-369, 2007.

[16] Kim, M. S., \& Yun, S. Y., Factors influencing flow state of cooperative learning among nursing students: in convergence era, Journal of Digital Convergence, Vol. 13 No.10, 397-403, 2015.

[17] Kırık, Ö. T., \& Boz, Y., Cooperative learning instruction for conceptual change in the concepts of chemical kinetics. Chemistry Education Research and Practice, Vol. 13, No.3, 221-236, 2012.

[18] Demir, I., Kilic, S., \& Depren, O., Factors Affecting Turkish Students' Achievement in Mathematics, Online Submission, Vol. 6, No. 6, 2009.

[19] Zorko, V., Factors affecting the way students collaborate in a wiki for English language learning, Australasian Journal of Educational Technology, 25(5), 2009.

[20] Ahmed, A., Factors Hindering the Implementation of Cooperative Learning in Secondary Schools of Harari Regional State, Ethiopia, International Journal of Research, 2011.

[21] Doymus, K., Teaching chemical equilibrium with the Jigsaw technique. Research Science Education, Vol. 38, 249-260, 2007.

[22] Belilew M., Practices and Challenges of Implementing Cooperative Learning: Ethiopian High Schools EFL Teachers Perspective, International Journal of Current Research, Vol. 7 No.12, 24584-24593, 2015.

[23] Muhammed K., Cooperative Learning Practices in College of Education and Behavioral Sciences in Haramaya University, International Journal of Science and Research, Vol. 3 No.11, 3044-3051, 2014.

[24] Abebaw Andargie, EFL Learner's Attitude towards Group Work: The Case of Higher and Lower Achievers, 2011.

[25] Wondwosen Tesfamichael, Students Attitude towards Cooperative Learning in EFL Writing Class, Educational Journal, Vol. 2 No. 3, 60-68, 2017.

[26] Amedu, O \& Gudi, K, Attitude of Students Towards Cooperative Learning In Selected Secondary Schools in Nasaraw State, Journal of Education and Practice, Vol. 8, No.1, 29-34, 2017.

[27] Byrne, B.M., Structural Equation Modeling with AMOS, basic concepts, applications, and programming, Routledge Taylor \& Francis Group, 2010.

[28] Slavin, R. E., Cooperative learning. Review of educational research, Vol. 50 No. 2, 315-342, 1980.

[29] DeVries, D. L., Edwards, K. J., \& Slavin, R. E., Biracial learning teams and race relations in the classroom: Four field 
experiments using Teams-Games-Tournament, Journal of Educational Psychology, Vol. 70 No. 3, 1978.

[30] Slavin, R. E., Student teams and achievement divisions, Journal of Research and Development in Education, Vol. 12, 39-49, 1978

[31] Aronson, E., The jigsaw classroom, Sage, 1978.

[32] Sharan, S., \& Sharan, Y, Small-Group Teaching, Englewood Cliffs, N. J.: Educational Technology Publications, 1976.

[33] Johnson, D. W., Johnson, R., Johnson, J., \& Anderson, D, The effects of cooperative vs. individualized instruction on student prosocial behavior, attitudes toward learning, and achievement, Journal of Educational Psychology, Vol. 68, 446-452, 1976.

[34] Johnson, D. W., Johnson, R., \& Scott, L, The effects of cooperative and individualized instruction on student attitudes and achievement. Journal of Social Psychology, 104, 207-216, 1978.

[35] Gillies, R. M., Ashman, A. F., \& Terwel, J., The teacher's role in implementing cooperative learning in the classroom: An introduction, The teacher's role in implementing cooperative learning in the classroom, 2007.

[36] Ruengtam, P., Modeling of Cooperative/Collaborative Learning Technique: A case study of interior architectural program, Procedia-Social and Behavioral Sciences, Vol. 105, 360-369, 2013.

[37] Antil, L., Jenkins, J., Wayne, S. \& Vadasy, P., Cooperative learning: Prevalance, conceptualizations, and the relation between research and practice, American Educational Research Journal, Vol. 35, No.3, 419-454, 1998. http://dx.doi.org/10.3102/00028312035003419.

[38] Belilew Molla, Practices and Challenges of Implementing Cooperative Learning: Ethiopian High Schools EFL Teachers Perspective, International Journal of Current Research, Vol. 7, No.12, 24584-24593, 2015.

[39] Weldemariam, N \& Girmay, T, The Practices of Student Network as Cooperative Learning in Ethiopia, African Education Review, Vol. 12, No.4, 696-712, 2015. DOI: 10.1080/18146627.2015.1112162.

[40] Slavin, R., Group rewards make groupwork work. Educational Leadership, Vol. 5, 89-91, 1991.

[41] Sharan, S., Cooperative learning in teams: Recent methods and effects on achievement, attitudes, and ethnic relations, Review of Educational Research, Vol. 50, 241-272, 1980.

[42] Johnson, D. W., \& Johnson, R., Cooperation and competition: theory and research, Edina, MN: Interaction Book Company, 1989.

[43] Johnson, D. W., \& Johnson, R., Instructional goal structure: Cooperative, competition, or individualistic, Review of
Educational Research, 44, 213-240, 1974.

[44] Clarke, N., Developing emotional intelligence abilities through team - based learning, Human Resource Development Quarterly, 21: 119-138, 2010. doi:10.1002/hrdq.20036

[45] Sisk, R.J., Team-based learning: Systematic research review, Journal of Nursing Education, 50, 665-669, 2011. doi:10.3928/01484834-20111017-01

[46] Gomez, E. A., Wu, D., \& Passerini, K., Computer-supported team-based learning: The impact of motivation, enjoyment and team contributions on learning outcomes, Computers \& Education, Vol. 55, No.1, 378-390, 2010.

[47] Roh, Y.S., Lee, S.J. and Mennenga, H., Team - based learning in nursing education. Nurs Health Sci, Vol. 16: 490-497, 2014. doi:10.1111/nhs. 12118

[48] Mohammad-Davoudi, Amir \& Parpouchi, Ashrafosadat. , Relation between Team Motivation, Enjoyment, and Cooperation and Learning Results in Learning Area Based on Team- based Learning among Students of Tehran University of Medical Science, Procedia - Social and Behavioral Sciences, 2016. doi: 10.1016/j.sbspro.2016.09.0 23.

[49] McInerney, M. J., \& Fink, L. D., Team-based learning enhances long-term retention and critical thinking in an undergraduate microbial physiology course, Microbiology education, Vol. 4, 3-12, 2003.

[50] Cohen, E., \& Lotan, R., (Eds.)., Working for equity in heterogeneous classrooms: Sociological theory in practice, New York: Teachers College Press, 1997.

[51] Arena, S. L., \& Davis, J. L. (2020). The concept-specific effects of cooperative learning in an introductory engineering mechanics dynamics course. Innovations in Education and Teaching International, 1-11.

[52] Morales, J. M., Olea, B., Atencia, M., \& Madrid, N. (2019, June). Fostering the cooperative learning of mathematics in engineering schools. In Proceedings of Teaching and Education Conferences (No. 8410856). International Institute of Social and Economic Sciences.

[53] Abd El Aliem, R. S., Sabry, S. S., \& MohyEl-Deen, H. F. (2019). Utilization of Jigsaw Cooperative Learning Strategy on Maternity Nursing Students' Attitude and Achievement. American Journal of Nursing, 8(6), 361-370.

[54] Uno, M., \& Katayama, Y. (2017). Learning outcomes using cooperative learning in communication classes: evaluation using text analysis. Open Journal of Nursing, 7(09), 1058.

[55] Mardanis, M., Sudargono, A., \& Rahman, M. K. (2019). THE EFFORT TO INCREASE STUDENT'S LEARNING OUTCOMES USING COOPERATIVE LEARNING EXAMPLE NON EXAMPLE. Journal of Geography Science and Education, 1(2), 101-109. 